\title{
LAMP3 is involved in tamoxifen resistance in breast cancer cells through the modulation of autophagy
}

\author{
Anika Nagelkerke ${ }^{1,2}$, Anieta M Sieuwerts ${ }^{3}$, Johan Bussink', Fred C G J Sweep ${ }^{2}$, \\ Maxime P Look ${ }^{3}$, John A Foekens ${ }^{3}$, John W M Martens ${ }^{3}$ and Paul N Span'
}

Departments of ${ }^{1}$ Radiation Oncology, ${ }^{2}$ Laboratory Medicine, Radboud University Nijmegen Medical Centre, PO Box 9101, 6500 HB Nijmegen, The Netherlands ${ }^{3}$ Department of Medical Oncology, Erasmus MC Cancer Institute and Cancer Genomics Netherlands, PO Box 2040, 3000 CA Rotterdam, The Netherlands
Correspondence should be addressed to P N Span

Email

P.Span@rther.umcn.nl

\begin{abstract}
Lysosome-associated membrane protein 3 (LAMP3) is a member of the LAMP-family of proteins, which are involved in the process of autophagy. Autophagy is induced by tamoxifen in breast cancer cells and may contribute to tamoxifen resistance. In this study, the significance of LAMP3 for tamoxifen resistance in breast cancer was examined. The methods employed included use of clonogenic assays to assess the survival of MCF7 breast cancer cells with LAMP3 knockdown after tamoxifen treatment and of quantitative real-time PCR of LAMP3 to evaluate its predictive value for first-line tamoxifen treatment in patients with advanced breast cancer. Results show that tamoxifen treatment of MCF7 cells induced LAMP3 mRNA expression. LAMP3 knockdown in these cells increased tamoxifen sensitivity. Evaluation of expression of the autophagy markers, LC3B and p62, after LAMP3 knockdown showed increased expression levels, indicating that cells with $\angle A M P 3$ knockdown have a suppressed ability to complete the autophagic process. In addition, knockdown of autophagy-associated genes resulted in sensitization to tamoxifen. Next, tamoxifen-resistant MCF7 cells were cultured. These cells had a sevenfold higher LAMP3 mRNA expression, showed elevated basal autophagy levels, and could be significantly resensitized to tamoxifen by $L A M P 3$ knockdown. In patients treated with first-line tamoxifen for advanced disease $(n=304)$, high LAMP3 mRNA expression was associated with shorter progression-free survival $(P=0.003)$ and shorter post-relapse overall survival $(P=0.040)$, also in multivariate analysis. Together, these results indicate that LAMP3 contributes to tamoxifen resistance in breast cancer. Tamoxifen-resistant cells are resensitized to tamoxifen by the knockdown of LAMP3. Therefore, LAMP3 may be clinically relevant to countering tamoxifen resistance in breast cancer patients.
\end{abstract} Key Words

Endocrine-Related Cancer (2014) 21, 101-112

\section{Introduction}

Tamoxifen, a non-steroidal anti-estrogen, has been used for more than 40 years as a hormonal therapeutic in estrogen receptor (ER)-positive breast cancer (Cole et al.
1971). Tamoxifen physically competes with estrogens to bind to the ER, thereby decreasing the proliferative stimuli of estrogens (Riggs \& Hartmann 2003). Despite its http://erc.endocrinology-journals.org DOI: 10.1530/ERC-13-0183
(C) 2014 Society for Endocrinology Printed in Great Britain
Published by Bioscientifica Ltd 
effectiveness in an adjuvant setting as well as in first-line therapy for advanced disease, a large group of patients will eventually develop resistance to tamoxifen (Maass et al. 1980). In theory, tumor cells lacking expression of the ER (ER-negatives) should be insensitive to tamoxifen treatment. Nevertheless, some ER-negative tumors show a good response, whereas not all ER-positive tumors respond to treatment with tamoxifen (Osborne et al. 1980). In general, two forms of resistance to anti-estrogens are recognized: intrinsic resistance and acquired resistance. Intrinsic resistance arises when there is no response from the onset of treatment. It is caused mainly by the lack of ER expression and therefore these tumors will not be treatable with anti-estrogens. However, other mechanisms may also influence intrinsic resistance. The mechanisms behind acquired resistance are more complex and are related to the development of insensitivity of the ER or alterations in signaling through the ER (Osborne 1998, Giuliano et al. 2011).

Treatment of breast cancer cells with tamoxifen was found to induce the process of autophagy (Greek for 'selfeating' and also referred to as macroautophagy; Bursch et al. 1996) and it has been suggested that autophagy contributes to tamoxifen resistance (Samaddar et al. 2008, Qadir et al. 2008). Autophagy is an evolutionarily conserved process, in which cellular components can be degraded and recycled in order to preserve energy (Klionsky \& Emr 2000). Cytoplasmic material is sequestered in double membrane vesicles, called autophagosomes. After fusion with lysosomes, the contents are degraded by lysosomal hydrolases. At basal levels, autophagy is crucial for cellular homeostasis in numerous physiological conditions, but also pathological disorders involve autophagy. In addition, autophagy can be a mechanism by which cells overcome stressful conditions. Survival of stress conditions, such as hypoxia and endoplasmic reticulum stress, can be mediated by a collection of pathways called the unfolded protein response (UPR; Feldman et al. 2005, Wouters \& Koritzinsky 2008). One arm of the UPR, the PKR-like endoplasmic reticulum kinase (PERK)/activating transcription factor 4 (ATF4)arm, was previously shown to induce autophagy (Milani et al. 2009, Rouschop et al. 2010, Rzymski et al. 2010). ATF4 is essential for hypoxia-induced autophagy, upregulating MAP1LC3B (referred to as LC3B; Rouschop et al. 2010, Rzymski et al. 2010). Recently, lysosome-associated membrane protein 3 (LAMP3) has been identified as a downstream target of the PERK/ATF4-arm of the UPR (Mujcic et al. 2009), induced by hypoxia and involved in hypoxia-mediated metastasis (Nagelkerke et al. 2011, 2013a). LAMP3 is a member of the so-called LAMP family, which plays an essential role in autophagy (Tanaka et al. 2000, Eskelinen et al. 2002). LAMP-proteins are thought to be responsible for the fusion of the autophagosome with the lysosome (Tanaka et al. 2000).

Recently, we have shown that LAMP3 has prognostic value for locoregional control in breast cancer (Nagelkerke et al. 2011). In addition, we have also found that LAMP3 mRNA expression was higher in ER-negative breast tumors, which basically have intrinsic resistance to tamoxifen. In this study, we have examined whether LAMP3 could promote tamoxifen resistance.

\section{Subjects and methods}

\section{Chemicals}

4-Hydroxytamoxifen and bafilomycin-A1 were purchased from Sigma-Aldrich.

\section{Cell culture}

Both MCF7 and MDA-MB-231 cells were obtained from LCG Promochem (London, UK) and used at between three and ten passages (except for the tamoxifen-resistant MCF7 clone). Identity of cell lines was authenticated by comparing growth properties and morphology, species confirmation was performed by using cytochrome oxidase I isoenzyme testing, and short tandem repeat analysis. Cell maintenance and experiments were performed in DMEM supplemented with 10\% (v/v) fetal bovine serum, $2 \mathrm{mM}$ L-glutamine, $20 \mathrm{mM}$ HEPES, $1 \times$ nonessential amino acids, and $10 \mathrm{U} / \mathrm{ml}$ penicillin and $10 \mu \mathrm{g} / \mathrm{ml}$ streptomycin (all from PAA, Cölbe, Germany) at $37^{\circ} \mathrm{C}$ with $5 \% \mathrm{CO}_{2}$. MCF7 cells were cultured to 4-hydroxytamoxifen resistance by adapting WT cells to $0.5 \mu \mathrm{M} 4$-hydroxytamoxifen and increasing the concentration by $0.5 \mu \mathrm{M}$ at a time. After several months, cells could tolerate $10 \mu \mathrm{M}$. These 4-hydroxytamoxifen-resistant cells were continuously passaged in the presence of $10 \mu \mathrm{M}$ 4-hydroxytamoxifen.

\section{Western blot analysis}

Western blotting was performed as described previously (Nagelkerke et al. 2011). Primary antibodies used were rabbit anti-LC3B (\#3868), rabbit anti-p62 (\#8025), rabbit anti-ATG5 (\#8540), rabbit anti-BECN1 (\#3495) (all from Cell Signaling Technology, Danvers, MA, USA) and mouse anti- $\alpha$-tubulin (Calbiochem, San Diego, CA, USA) all diluted 1:1000. Densitometric analysis of western blots was performed using ImageJ (National Institutes of Health,

Published by Bioscientifica Ltd. 
Bethesda, MA, USA). Western blot analysis of autophagy markers was interpreted according to previously published guidelines (Klionsky et al. 2008, Mizushima et al. 2010). Western blots were cropped for the purposes of clarity.

\section{Quantitative real-time PCR of cell lines}

RNA was isolated using the Total RNA Purification Kit from Norgen Biotek Corp. (Thorold, ON, Canada) with an on-column DNase treatment. RNA (1 mg) was reverse transcribed with the iScript cDNA synthesis kit, according to the manufacturer's instructions. mRNA expression of reverse transcribed LAMP3 was analyzed using quantitative real-time PCR (RT-qPCR) on a CFX96 real-time PCR detection system (Bio-Rad Laboratories, Inc.) with SYBR Green (Applied Biosystems) and the following primers: LAMP3: F, 5'-TGAAAACAACCGATGTCCAA-3' and R, 5'-TCAGACGAGCACTCATCCAC-3'; MAP1LC3B:

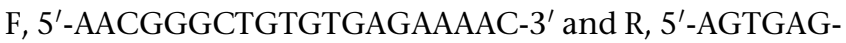
GACTTTGGGTGTGG-3'; ATG5: F, 5'-GCAAGCCAGACAGGAAAAAG-3' and R, 5'-GACCTTCAGTGGTCCGGTAA-3'; BECN1: F, 5'-AGGTTGAGAAAGGCGAGACA-3' and R, 5'-AATTGTGAGGACACCCAAGC-3'; ESR1 (ER $\alpha)$ : F, 5'-CCACCAACCAGTGCACCATT- $3^{\prime}$ and R, 5'-GGTCTTTTCGTATCCCACCTTTC- ${ }^{\prime}$; and $P G R$ (progesterone receptor): F, 5'-CGCGCTCTACCCTGCACTC-3' and R, 5'-TGAATCCGGCCTCAGGTAGTT-3'. qPCR was performed for 40 cycles at $95^{\circ} \mathrm{C}$ for 15 seconds and $60^{\circ} \mathrm{C}$ for 60 seconds. Expression of the reference gene HPRT1 (hypoxanthine phosphoribosyl transferase 1) was analyzed using a predeveloped assay from Applied Biosystems (Hs.412707).

\section{Stable LAMP3 transfections}

Constructs of short hairpin RNAs (shRNA) targeting LAMP3 or a noncoding sequence were kindly provided by Prof. B Wouters (Ontario Cancer Institute, Toronto, ON, Canada). Lentiviral pseudotyped particles were formed in HEK293FT cells with the ViraPower lentiviral expression system according to the manufacturer's instructions (Invitrogen). MCF7 and MDA-MB-231 cells were infected at a low passage number. The transfected cells were selected by puromycin $(4 \mu \mathrm{g} / \mathrm{ml})$ treatment for $\sim 10$ days.

\section{Transient transfections}

siRNA-mediated knockdowns were performed using SaintRed (Synvolux Therapeutics, Groningen, The Netherlands) according to the manufacturer's instructions. siRNAs were from Sigma-Aldrich: MAP1LC3B, SASI_Hs01_00212376 and SASI_Hs02_00356118; ATG5, SASI_Hs02_00338435 and SASI_Hs01_00173158; BECN1, SASI_Hs01_00090914 and SASI_HSO2_00336256; and LAMP3, SASI_Hs01_ 00214236 and SASI_Hs02_00345584.

\section{Colony-forming assays after tamoxifen treatment}

Clonogenic cell survival was analyzed by plating 500 cells in T25 bottles. The cells were allowed to adhere overnight before treatment with the indicated concentrations of 4-hydroxytamoxifen for $24 \mathrm{~h}$. Tamoxifen-containing medium was replaced with normal cell culture medium, after which colonies were allowed to form. Concentrations of 4-hydroxytamoxifen were lower for MCF7 cells compared with MDA-MB-231 cells to maximally visualize the dose-response curves. Once colonies in the control flasks comprised at least 50 cells (up to 10 days), cells were fixed for $10 \mathrm{~min}$ in $70 \%$ ethanol at $4{ }^{\circ} \mathrm{C}$. Colonies were stained with $0.5 \%(\mathrm{w} / \mathrm{v})$ crystal violet (Sigma-Aldrich). Colonies of 50 cells or more were scored manually.

\section{Immunocytochemistry}

Cells were grown on coverslips and fixed for $10 \mathrm{~min}$ in ice-cold methanol. Staining was performed as described previously (Nagelkerke et al. 2011) with minor modifications. Primary antibodies used were biotin-conjugated mouse anti-LC3 (NanoTools, Teningen, Germany) 1:100 and rabbit anti-LAMP1 (Cell Signaling Technology) 1:250. Cy3-conjugated mouse anti-biotin (Jackson ImmunoResearch Laboratories, Inc., West Grove, PA, USA) and Alexa488-conjugated donkey anti-rabbit (Invitrogen) both diluted at the ratio of 1:600 were used as the secondary antibodies.

\section{Patients}

Total RNA extracted from frozen ER-positive primary breast tumor tissue specimens obtained, as described previously (Sieuwerts et al. 2005), from female patients with operable breast cancer, who were entering the clinic between 1981 and 1996, was used. Cytosolic tumor protein expression levels of ER were determined as described previously (Foekens et al. 1989) and tumors with $\geq 10 \mathrm{fmol} / \mathrm{mg}$ protein were classified as ER-positive. All patients included developed a measurable recurrence during follow-up and were treated with first-line tamoxifen (40 mg daily). To meet Reporting Recommendations for Tumor Marker Prognostic Studies (REMARK)

Published by Bioscientifica Ltd. 
recommendations (Altman et al. 2012), we have provided the inclusion criteria for final analysis in this study: i) at least $100 \mathrm{mg}$ freshly frozen tumor material available, ii) more than $30 \%$ epithelial tumor cell nuclei in hematoxylin/eosin-stained sections, iii) specimen of good RNA quality and sufficient quantity according to predefined criteria, and last but not least iv) adherence to predefined clinical inclusion criteria. Full details of these quality and quantity controls as well as the clinical inclusion criteria have been described previously (Sieuwerts et al. 2005). After applying these criteria, 304 patients remained. Relevant clinicopathological characteristics of the patients and their primary tumors are presented in Table 1. The median follow-up time of living patients was 43 months, range 4-149 months. Two hundred and fifteen patients (71\%) did not receive prior adjuvant systemic therapy, while 57 patients (19\%) were previously treated with adjuvant chemotherapy (35 patients (12\%) with nonanthracycline-based (cyclophosphamide, methotrexate and fluorouracil (CMF)) and 22 patients (7\%) with anthracycline-based (fluorouracil, adriamycin, and cyclophosphamide/fluorouracil, epirubicin and cyclophosphamide (FAC/FEC)) regimens). Thirty patients (10\%) presented with distant metastases at initial diagnosis (M1 patients), two patients were not without disease after primary surgery. Progression-free survival (PFS) was defined as the time elapsed between initiation of tamoxifen therapy and first detection of disease progression as defined by the standard of International Union against Cancer criteria (Hayward et al. 1977). Our studies on prognostic and predictive markers have been approved by the Medical Ethics Committee of the Erasmus MC, Rotterdam, The Netherlands (MEC 02.953). Furthermore, this retrospective study was performed in accordance with the Code of Conduct of the Federation of Medical Scientific Societies in The Netherlands (http://www.fmwv.nl).

\section{RT-qPCR of clinical samples}

RT-qPCR was used to measure ESR1, PGR, ERBB2, and $L A M P 3$ expression from the cDNA preparations

Table 1 Associations of LAMP3 mRNA expression levels with clinicopathological factors. LRR, local-regional recurrence.

\begin{tabular}{l} 
\\
\\
\hline Total \\
Age in categories (years) \\
$\left(r_{\mathrm{s}}=-0.10\right)$ \\
$\leq 55$ \\
$56-70$ \\
$>70$ \\
Menopausal status \\
Premenopausal \\
Postmenopausal \\
Tumor size \\
pT1 \\
pT2 + unknown \\
pT3/4 \\
Disease-free interval (months) \\
$\leq 12$ \\
$12-36$ \\
$>36$ \\
Dominant site of relapse \\
Soft tissue (LRR) \\
Bone \\
Viscera (other) \\
ERBB2 mRNA \\
Low \\
High \\
Unknown \\
ER mRNA ( $\left.r_{\mathrm{s}}=-0.30\right)$ \\
$P G R$ mRNA ( $\left.r_{\mathrm{s}}=-0.16\right)$ \\
\end{tabular}

\begin{tabular}{ccc}
$\begin{array}{c}\text { No. of } \\
\text { patients }\end{array}$ & & $\%$ \\
\hline 304 & & 100
\end{tabular}

\begin{tabular}{l} 
Median \\
\hline 0.0048 \\
\\
0.0050 \\
0.0045 \\
0.0048 \\
0.0048 \\
0.0048 \\
0.0048 \\
0.0048 \\
0.0049 \\
0.0038 \\
0.0046 \\
0.0072 \\
0.0103 \\
0.0042 \\
0.0057 \\
0.0044 \\
0.0095 \\
\end{tabular}

$\frac{\text { Interquartile range }}{0.012} \frac{\boldsymbol{P} \text { value* }}{0.092^{\mathrm{a}}}$

$\begin{array}{rl}119 & 39 \\ 110 & 36 \\ 75 & 25 \\ 79 & 26\end{array}$

225 74

\section{3}

181

40

27

60

\section{6}

133

95

25

44

31

$35 \quad 12$

157

112

52

37

257

40

85

13

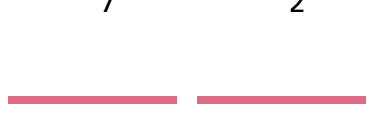

*Two-sided $P$ value.

aspearman's rank correlation.

bMann-Whitney U-test.

${ }^{c}$ Kruskal-Wallis test, a nonparametric test for trend was not applicable.

${ }^{d}$ Kruskal-Wallis test, followed by a nonparametric test for trend. http://erc.endocrinology-journals.org DOI: 10.1530/ERC-13-0183
CC 2014 Society for Endocrinology Printed in Great Britain
Published by Bioscientifica Ltd.

$\begin{array}{lc}0.016 & \\ 0.013 & \\ 0.008 & 0.34^{\mathrm{b}} \\ 0.016 & \\ 0.011 & 0.84^{\mathrm{c}} \\ 0.019 & \\ 0.010 & \\ 0.011 & 0.038^{\mathrm{d}} \\ 0.007 & \\ 0.011 & \\ 0.016 & 0.034^{\mathrm{d}} \\ 0.020 & \\ 0.010 & \\ 0.013 & 0.036^{\mathrm{b}} \\ 0.010 & \\ 0.017 & <0.001^{\mathrm{a}} \\ & 0.004^{\mathrm{a}} \\ \end{array}$


generated as described previously (Sieuwerts et al. 2005, van Agthoven et al. 2009) using the TaqMan Hs0018088 m1 gene expression assay from Applied Biosystems to measure LAMP3. For the clinical cohort, expression levels were normalized against the average expression levels of three reference genes (HMBS, HPRT1, and B2M) as described previously (Sieuwerts et al. 2005).

\section{Statistical analysis}

Statistical analysis of in vitro data was performed using Student's $t$-tests. Statistical significance was set at twosided $P$ values $<0.05$. Asterisks indicate statistical significance, where ${ }^{*} P<0.05,{ }^{* *} P<0.01$, and ${ }^{* * *} P<0.001$.

Differences in levels between grouping variables among patient and tumor characteristics were assessed with the Mann-Whitney $U$-test or Kruskal-Wallis test, including a Wilcoxon-type test for trend, when appropriate. The strengths of the associations between continuous variables were tested with Spearman's rank correlation $\left(r_{\mathrm{s}}\right)$. Expression levels of LAMP3, ERBB2, ESR1, and $P G R$ mRNA were transformed to reduce distribution skewness to allow the use of a Cox proportional hazard model to calculate the hazard ratio (HR) and 95\% $\mathrm{CI}$ in the analysis of PFS. Three equal thirds were used to categorize the variables as low, intermediate, and high.

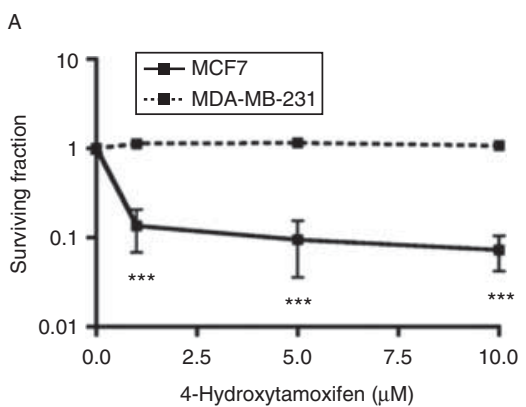

C

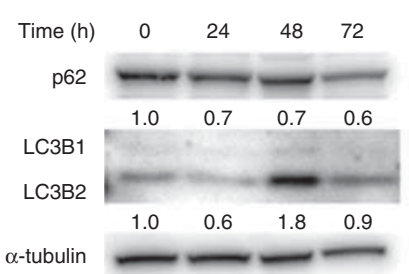

Figure 1

Effect of tamoxifen treatment on MCF7 and MDA-MB-231 cells. (A) Clonogenic survival of MCF7 and MDA-MB-231 cells after treatment with 4-hydroxytamoxifen for $24 \mathrm{~h}$. (B) LAMP3 mRNA expression in MCF7 and MDA-MB-231 cells after treatment with 4-hydroxytamoxifen for $24 \mathrm{~h}$ Asterisks indicate statistical significance compared with the corresponding control. Data are presented as mean values + s.D. Measurements were carried
Survival curves were generated using the method of Kaplan \& Meier and the log-rank test was used to test for differences.

\section{Results}

\section{4-Hydroxytamoxifen treatment of MCF7 cells reduces their survival and induces LAMP3 expression and autophagy}

First, the effect of 4-hydroxytamoxifen, an active metabolite of tamoxifen, on survival of two commonly used breast cancer cell lines was examined. ER-positive MCF7 and ER-negative MDA-MB-231 breast cancer cells were treated with increasing concentrations of 4-hydroxytamoxifen, after which clonogenic survival was evaluated. MCF7 cells showed a significant reduction in cell survival at $1 \mu \mathrm{M}$ and higher, whereas MDA-MB-231 cells did not show any decrease in survival with up to $10 \mu \mathrm{M}$ of 4-hydroxytamoxifen (see Fig. 1A). Next, the effect of tamoxifen on the mRNA expression of $L A M P 3$ was evaluated. Figure 1B shows that treatment of MCF7 cells with increasing concentrations of 4-hydroxytamoxifen led to a dose-dependent induction of LAMP3 mRNA expression. However, in MDA-MB-231 cells this response was absent, despite the clear

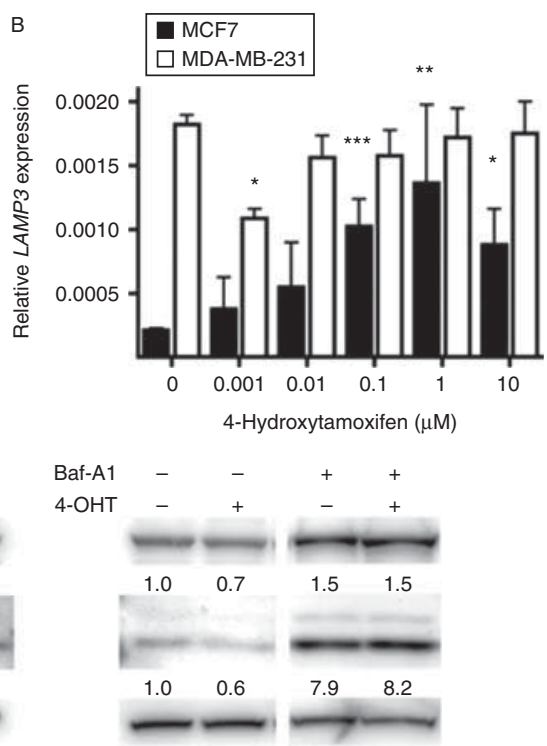

out in two independent experiments with three replicates each. (C) Western blot analysis for p62, LC3B, and $\alpha$-tubulin of MCF7 cells after treatment with $5 \mu \mathrm{M}$ 4-hydroxytamoxifen (4-OHT) for the time indicated. Cells were also treated with a combination of $5 \mu \mathrm{M}$ 4-hydroxytamoxifen with $100 \mathrm{ng} / \mathrm{ml}$ bafilomycin-A1 (Baf-A1) for $24 \mathrm{~h}$. Numbers below the bands indicate results from densitometric analysis relative to the corresponding $\alpha$-tubulin.

Published by Bioscientifica Ltd. 
upregulation of $L A M P 3$ in this cell line by other drugs and stresses found previously (Mujcic et al. 2009, Nagelkerke et al. 2011). It appears that in these two cell lines, LAMP3 induction is only present in cells that are sensitive to tamoxifen. Subsequently, the effect of 4-hydroxytamoxifen on autophagy was studied in MCF7 cells using western blot analysis for p62 and LC3B, two autophagosomal markers (Mizushima et al. 2010). Treatment with $5 \mu \mathrm{M}$ 4-hydroxytamoxifen for up to $72 \mathrm{~h}$ reduced the expression of p62 (see Fig. 1C). At $48 \mathrm{~h}$ of exposure, MCF7 cells showed a strong induction of LC3B2, but this was reduced to basal levels by $72 \mathrm{~h}$. As p62 is reported to inversely correlate with autophagy levels, these data collectively indicate that 4-hydroxytamoxifen can induce autophagy in MCF7 cells. This was verified further by exposing MCF7 cells to both 4-hydroxytamoxifen and the autophagy inhibitor bafilomycin-A1. Bafilomycin-A1 blocks fusion of the autophagosome with the lysosome. During exposure to bafilomycin-A1, tamoxifen-treated cells showed an increase in both p62 and LC3B2 expression compared with cells not treated with bafilomycin-A1 (see Fig. 1C). This indicates that the autophagic flux is upregulated during tamoxifen treatment.

\section{LAMP3 knockdown inhibits autophagy and sensitizes MCF7 cells to treatment with 4-hydroxytamoxifen}

To evaluate the role of LAMP3 in tamoxifen-induced autophagy, MCF7 and MDA-MB-231 cells were subjected to shRNA-mediated LAMP3 knockdown. Both shRNAs could reduce the mRNA expression of LAMP3 by at least 75\% (see Fig. 2A). Next, the basal autophagy activity was evaluated in the LAMP3 knockdowns by western blotting for p62 and LC3B. Both p62 and LC3B2 expression levels were elevated in the LAMP3 knockdown cells (see Fig. 2B). This increased expression of $\mathrm{p} 62$ and LC3B2 indicates that autophagy is compromised in the LAMP3 knockdown cells. Considering the localization of the LAMP proteins in the lysosomal membrane, the autophagic pathway is potentially blocked during fusion of the autophagosome with the lysosome. Treatment of MCF7 LAMP3 knockdown cells with $5 \mu \mathrm{M}$ 4-hydroxytamoxifen led to a slight increase in both LC3B2 and p62 levels (see Fig. 2B). This suggests that tamoxifen induces autophagy to a lesser extent in LAMP3 knockdown cells and that these cells are indeed autophagy-compromised. To validate whether autophagy is comprised after LAMP3 knockdown, both control and LAMP3 knockdown cells were cultured on coverslips and stained against LC3B and LAMP1 to
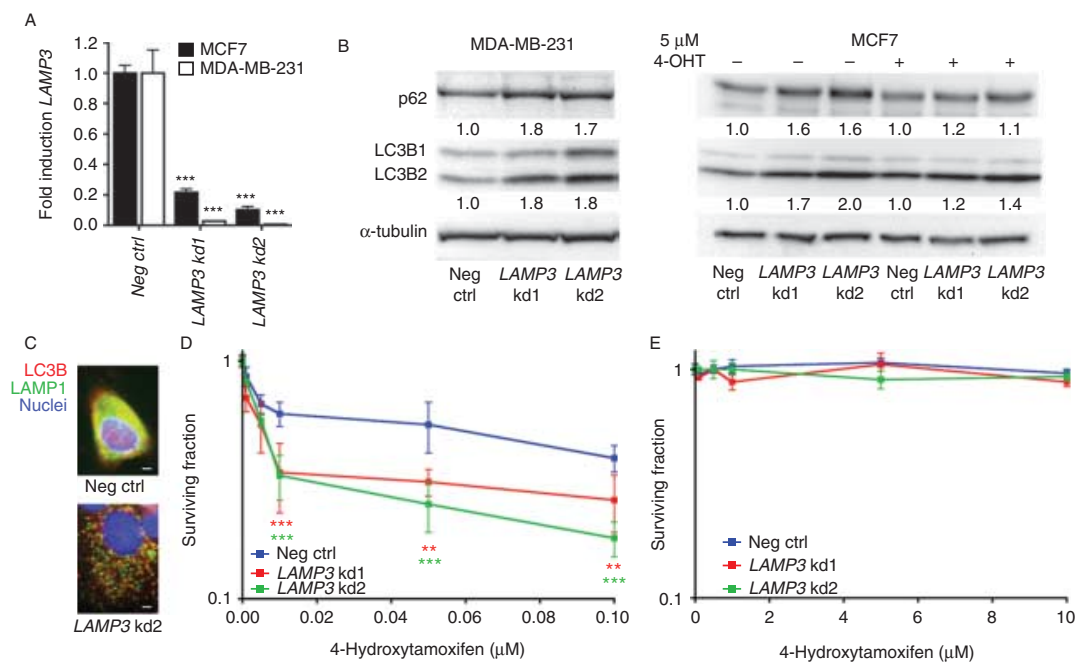

Figure 2

Effect of $L A M P 3$ knockdown on tamoxifen sensitivity. (A) LAMP3 mRNA expression of MCF7 and MDA-MB-231 cells after shRNA-mediated knockdown of $L A M P 3$. (B) Western blot analysis for autophagy markers in MDA-MB-231 and MCF7 cells after shRNA-mediated knockdown of LAMP3. MCF7 cells with knockdown of $L A M P 3$ were also treated with $5 \mu \mathrm{M}$ 4-hydroxytamoxifen (4-OHT) for $24 \mathrm{~h}$. Numbers below the bands indicate the results of densitometric analysis relative to the corresponding $\alpha$-tubulin. (C) Immunocytochemical staining of LC3B (red), LAMP1 (green), and nuclei (blue) in MCF7 control and LAMP3 knockdown cells. Scale bars $=10 \mu \mathrm{m}$. (D) Clonogenic survival of MCF7 cells after shRNA-mediated knockdown of $L A M P 3$ and treatment with 4-hydroxytamoxifen for $24 \mathrm{~h}$. (E) Clonogenic survival of MDA-MB-231 cells after shRNA-mediated knockdown of $\angle A M P 3$ and treatment with 4-hydroxytamoxifen for $24 \mathrm{~h}$. Asterisks indicate statistical significance compared with the corresponding control. Data are presented as mean values \pm s.D. Measurements were carried out in two independent experiments with three replicates each. http://erc.endocrinology-journals.org DOI: 10.1530/ERC-13-0183
(C) 2014 Society for Endocrinology Printed in Great Britain
Published by Bioscientifica Ltd 
visualize autophago(lyso)somes and lysosomes respectively (see Fig. 2C). Overall, the expression of both markers was increased and more punctate in the LAMP3 knockdown cells. In addition, vesicles were larger in the knockdown cells. Higher levels of LC3B in LAMP3 knockdown cells are in accordance with the western blot data. Furthermore, in LAMP3 knockdown cells very little colocalization between LAMP1 and LC3B puncta could be found, indicating that indeed fusion of the autophagosome with the lysosome is inhibited. To examine the role of LAMP3 in sensitivity to tamoxifen treatment, MCF7 cells with a stable knockdown of $L A M P 3$ were exposed to 4-hydroxytamoxifen. Figure 2D shows the clonogenic survival of these cell lines. It was found that LAMP3 knockdown in the ER-positive MCF7 cells enhances sensitivity to cell death induced by 4-hydroxytamoxifen. On the other hand, the ER-negative MDA-MB-231 cells did not respond to 4-hydroxytamoxifen treatment, and LAMP3 knockdown could not sensitize these cells to 4-hydroxytamoxifen (see Fig. 2E).

\section{Knockdown of autophagy-associated genes sensitizes MCF7 cells to treatment with 4-hydroxytamoxifen}

Next, the role of autophagy in 4-hydroxytamoxifen sensitivity was assessed in MCF7 cells. With siRNA-mediated

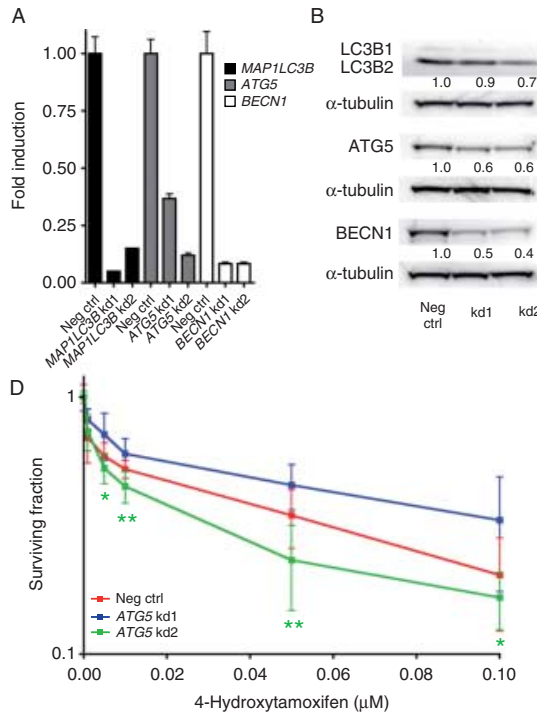

Figure 3

Effect of knockdown of autophagy genes on tamoxifen sensitivity. (A) mRNA expression of MAP1LC3B, ATG5, and BECN1 in MCF7 cells after siRNA-mediated knockdown of these genes. (B) Western blot analysis of LC3B, ATG5, and BECN1 in MCF7 cells after siRNA-mediated knockdown of these genes. Numbers below the bands indicate results from densitometric analysis relative to the corresponding $\alpha$-tubulin. Clonogenic survival of knockdown, mRNA expression of the autophagyassociated genes MAP1LC3B, ATG5, and BECN1 was successfully abolished (see Fig. 3A). Figure 3B shows that knockdown is also present at the protein level although to a lesser extent. Knockdown of $A T G$ genes was previously shown to result in an inhibition of autophagy (Mizushima et al. 2010). In this study, in general, the siRNA-mediated knockdowns could sensitize MCF7 cells to treatment with 4-hydroxytamoxifen, although some siRNAs were more effective that others (see Fig. 3C, D and E).

Tamoxifen-resistant cells have higher mRNA expression of LAMP3, show induced levels of autophagy, and can be resensitized to tamoxifen treatment by LAMP3 knockdown

To study the effect of tamoxifen resistance on LAMP3 expression, MCF7 cells were cultured to 4-hydroxytamoxifen resistance. Initially, WT cells were exposed to $0.5 \mu \mathrm{M}$ 4-hydroxytamoxifen. Once cells had adapted to this dose, the concentration was increased stepwise with $0.5 \mu \mathrm{M} 4$-hydroxytamoxifen. This process was repeated for several months until the cells could tolerate $10 \mu \mathrm{M}$ 4-hydroxytamoxifen. Proliferation of this tamoxifen-resistant cell population was slower than that of the WT cells. Analysis of mRNA expression for both
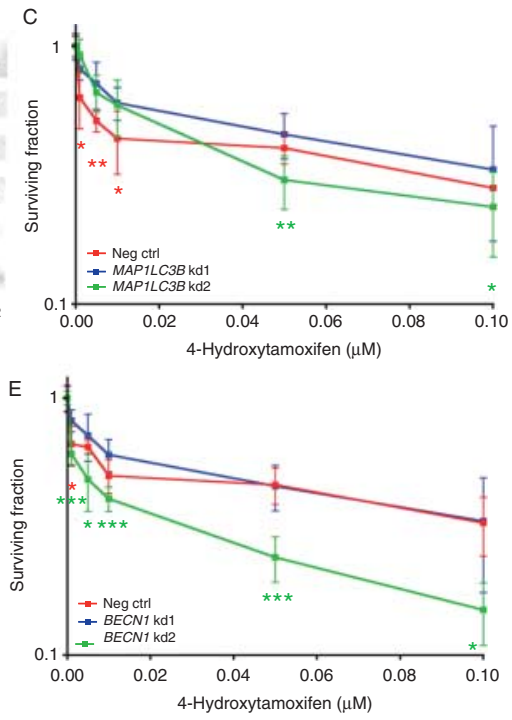

MCF7 cells after siRNA-mediated knockdown of (C) MAP1LC3B, (D) ATG5, and (E) BECN1 and treatment with 4-hydroxytamoxifen for $24 \mathrm{~h}$. Asterisks indicate statistical significance compared with the corresponding control. Data are shown as mean values \pm s.D. Measurements were carried out in two independent experiments with three replicates each.

Published by Bioscientifica Ltd. 
the ER and $P G R$ revealed that these tamoxifen-resistant cells still expressed the $E R$, albeit to a lesser extent, whereas the PGR was lost completely (see Fig. 4A). Compared with WT MCF7 cells, the tamoxifen-resistant cells showed a significant increase in levels of $L A M P 3$ mRNA expression (see Fig. 4B). In addition, tamoxifen resistant MCF7 cells showed altered levels of basal autophagy, as suggested by the decreased LC3B2 and p62 expression levels (see Fig. 4C). To see whether the decrease in LC3B2 represented a reduction in autophagosomes or an increased turnover of autophagosomes, fusion of the autophagosomes with the lysosomes was blocked by bafilomycin-A1 treatment. In both WT and tamoxifen-resistant cells, LC3B2 and p62 accumulated (see Fig. 4C). This indicates that autophagosomes are not reduced in tamoxifen-resistant cells, as LC3B2 is present in similar quantities in WT and resistant cells after bafilomycin-A1 treatment. Therefore, tamoxifen-resistant cells appear to have an increased turnover of autophagosomes compared with WT cells.
Next, siRNA-mediated knockdown of LAMP3 was applied to tamoxifen-resistant cells (see Fig. 4D). The siRNAs used successfully abrogated LAMP3 mRNA expression by at least $60 \%$. Subsequently, the sensitivity of these tamoxifenresistant $L A M P 3$ knockdown cells was evaluated. Figure $4 \mathrm{E}$ shows that knockdown of LAMP3 in combination with treatment with $10 \mu \mathrm{M}$ 4-hydroxytamoxifen could resensitize tamoxifen-resistant MCF7 cells to tamoxifen.

\section{LAMP3 mRNA expression in patients with advanced breast cancer}

As LAMP3 was associated with tamoxifen resistance in cultured breast cancer cells, the association of LAMP3 mRNA with response to first line tamoxifen treatment was investigated in 304 patients with advanced breast cancer. As shown in Table 1, LAMP3 mRNA levels were higher in patients with soft tissue metastases compared with patients with nonsoft tissue or bone metastases $(P=0.034)$.
A

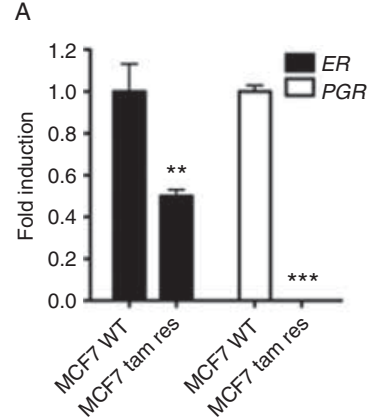

D

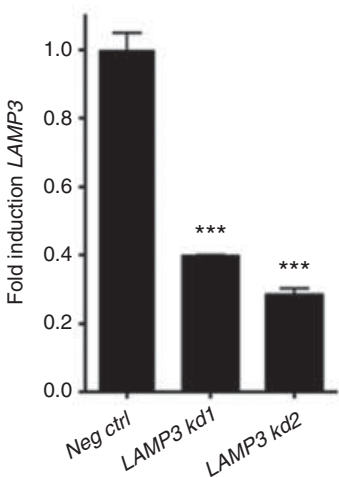

B

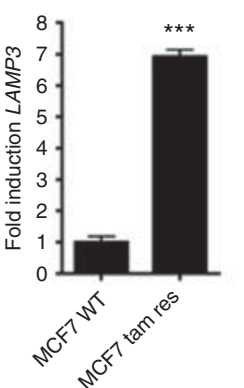

C

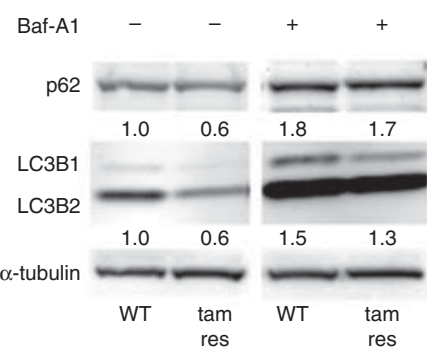

E

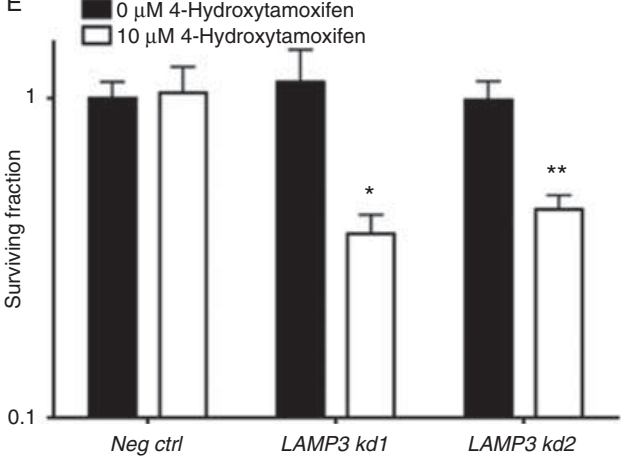

Figure 4

Effect of knockdown of LAMP3 on tamoxifen sensitivity in MCF7 tamoxifen-resistant cells. (A) mRNA expression of ER and PGR in MCF7 cells cultured to be resistant to $10 \mu \mathrm{M}$ 4-hydroxytamoxifen. (B) mRNA expression of LAMP3 in MCF7 cells cultured to $10 \mu \mathrm{M}$ 4-hydroxytamoxifen resistance. (C) Western blot analysis of p62 and LC3B in MCF7 cells cultured to $10 \mu \mathrm{M}$ 4-hydroxytamoxifen resistance with and without treatment with $100 \mathrm{ng} / \mathrm{ml}$ bafilomycin-A1 for $24 \mathrm{~h}$. Numbers below the bands indicate measurements from densitometric analysis relative to the corresponding $\alpha$-tubulin. http://erc.endocrinology-journals.org DOI: 10.1530/ERC-13-0183
(C) 2014 Society for Endocrinology Printed in Great Britain
(D) mRNA expression of LAMP3 after siRNA-mediated knockdown in MCF7 tamoxifen-resistant cells. (E) Clonogenic survival of MCF7 tamoxifenresistant cells after siRNA-mediated knockdown of LAMP3 and treatment with $10 \mu \mathrm{M}$ 4-hydroxytamoxifen for $24 \mathrm{~h}$. Asterisks indicate statistical significance compared with the corresponding control. Shown are mean values \pm s.D. Measurements were carried out in two independent experiments with three replicates each. 
LAMP3 mRNA expression was also higher in ERBB2-high tumors $(P=0.036)$ and correlated negatively with expression of ESR1 $\left(r_{\mathrm{s}}=-0.30, P<0.001\right)$ and PGR $\left(r_{\mathrm{s}}=-0.16\right.$, $P=0.004)$. Interestingly, in these patients high LAMP3 mRNA expression was associated with a shorter PFS time $(P=0.003)$ and a shorter post-relapse overall survival time $(P=0.040)$ after start of tamoxifen treatment for advanced disease (see Fig. 5A and $B$ respectively). The patients with the highest tertile of $L A M P 3$ expression had
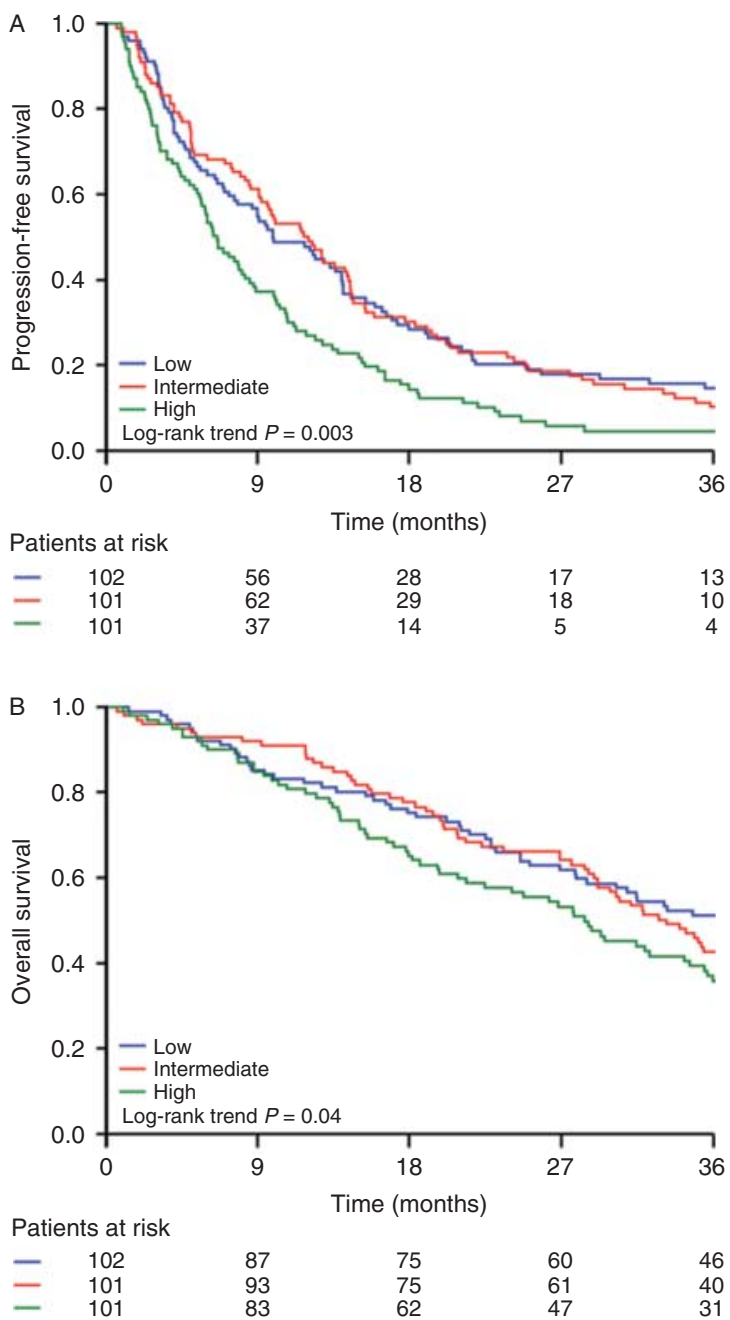

\section{Figure 5}

Kaplan-Meier survival curves. Patients were divided into three equally sized groups based on $L A M P 3$ mRNA expression levels in the primary tumor (low, intermediate, and high LAMP3 mRNA expression). (A) Kaplan-Meier progression-free survival curves. High mRNA expression of LAMP3 is associated with shorter median progression-free survival time $(P=0.003)$. (B) Kaplan-Meier post-relapse overall survival curves. High mRNA expression of $\angle A M P 3$ is associated with shorter post-relapse median overall survival time $(P=0.040)$. The number of patients at risk is indicated the bottom of the graphs at different time points during follow-up. Low LAMP3 mRNA expression is represented by the blue, intermediate by the red, and high by the green lines. a worse PFS after start of first-line tamoxifen in both Cox univariate $(\mathrm{HR}=1.57,95 \% \mathrm{CI}=1.18-2.09, P<0.001)$ and multivariate $(\mathrm{HR}=1.37,95 \% \mathrm{CI}=1.01-1.86, P=0.032)$ analyses (see Table 2). Median PFS for the tertile with low LAMP3 expression was 9.9 months (95\% CI $=7.3-14.0)$, for the intermediate group 12.0 months $(95 \% \mathrm{CI}=9.0-14.4)$, and 6.6 months $(95 \% \mathrm{CI}=5.5-8.2)$ for the high expression group.

\section{Discussion}

In this study, we found that knockdown of LAMP3 in the ER-positive MCF7 breast cancer cell line can sensitize cells to treatment with tamoxifen and can even revert acquired resistance to tamoxifen. In addition, LAMP3 was found to play a functional role in autophagy. This could explain its association with tamoxifen sensitivity, as knockdown of the more crucial autophagy genes $L C 3 B, A T G 5$, and $B E C N 1$ also led to a sensitization to treatment with tamoxifen. mRNA expression assessed in a cohort of advanced breast tumors showed that LAMP3 levels are associated with disease progression during tamoxifen treatment.

Tamoxifen is an anti-estrogen that has proven its value in the treatment of ER-positive breast cancer. However, not all ER-positive tumors will initially respond to tamoxifen and, perhaps more importantly, responding tumors will eventually develop resistance. Therefore, it is of vital importance to identify the factors and mechanisms involved in tamoxifen resistance. Several studies have previously identified so-called BCAR (breast cancer anti-estrogen resistance) genes (van Agthoven et al. 2010, Duan et al. 2011). In this study, we have shown that LAMP3 is also a factor involved in anti-estrogen resistance.

LAMP3 expression is induced via the PERK/ATF4-arm of the UPR (Mujcic et al. 2009). The UPR and its associated factors have been implicated in resistance to numerous cancer therapies (Pyrko et al. 2007, Scriven et al. 2009, Al-Rawashdeh et al. 2010, Chen et al. 2011). For example, increased expression of $A T F 4$ is associated with decreased sensitivity to several therapies (Tanabe et al. 2003, Igarashi et al. 2007). Recently, overexpression of X-box-binding protein 1 (XBP1), a downstream factor in the UPR, has been shown to lead to a reduced sensitivity of ER-positive breast cancer cells to anti-estrogen treatment (Gomez et al. 2007). Also, knockdown of glucose-related protein 78 (GRP78), a major player in the UPR, could restore antiestrogen sensitivity in resistant cells, whereas GRP78 overexpression caused resistance in sensitive cells (Cook et al. 2012). Together with the results from our current

Published by Bioscientifica Ltd. 
Table 2 Cox univariate and multivariate analyses for PFS of categorized LAMP3 in estrogen receptor-positive tumors from 304 patients whose recurrence was treated with first-line tamoxifen monotherapy

\begin{tabular}{|c|c|c|c|c|c|c|c|c|}
\hline \multirow[b]{2}{*}{ Factor of base model } & \multirow{2}{*}{$\begin{array}{c}\begin{array}{c}\text { No. of } \\
\text { patients }\end{array} \\
304\end{array}$} & \multirow{2}{*}{$\begin{array}{c}\% \\
100\end{array}$} & \multicolumn{3}{|c|}{ Univariate analysis } & \multicolumn{3}{|c|}{ Multivariate analysis $^{a}$} \\
\hline & & & $\mathrm{HR}$ & $95 \% \mathrm{Cl}$ & $P$ value & $\mathrm{HR}$ & $95 \% \mathrm{Cl}$ & $P$ value \\
\hline Age (years) & & & & & 0.036 & & & 0.29 \\
\hline$\leq 55$ & 119 & 39 & 1.00 & & & 1.00 & & \\
\hline $56-70$ & 110 & 36 & 0.83 & $0.63-1.08$ & & 0.87 & $0.65-1.17$ & \\
\hline$>70$ & 75 & 25 & 0.67 & $0.50-0.91$ & & 0.77 & $0.55-1.07$ & \\
\hline Menopausal status & & & & & 0.26 & & & \\
\hline Premenopausal & 79 & 26 & 1.00 & & & & & \\
\hline Postmenopausal & 225 & 74 & 0.86 & $0.66-1.12$ & & & & \\
\hline $\begin{array}{l}\text { Disease-free interval } \\
\text { (months) }\end{array}$ & & & & & $<0.001$ & & & $<0.001$ \\
\hline$\leq 12$ & 76 & 25 & 1.00 & & & 1.00 & & \\
\hline $12-36$ & 133 & 44 & 0.64 & $0.48-0.86$ & & 0.67 & $0.50-0.90$ & \\
\hline$>36$ & 95 & 31 & 0.54 & $0.39-0.74$ & & 0.54 & $0.39-0.74$ & \\
\hline Dominant site of relapse & & & & & 0.63 & & & 0.33 \\
\hline LRR & 35 & 11 & 1.00 & & & 1.00 & & \\
\hline Bone & 157 & 52 & 1.20 & $0.82-1.77$ & & 1.19 & $0.80-1.79$ & \\
\hline Other & 112 & 37 & 1.18 & $0.79-1.76$ & & 1.35 & $0.89-2.06$ & \\
\hline$E R$ mRNA level & 304 & 100 & 0.75 & $0.65-0.87$ & $<0.001$ & 0.77 & $0.66-0.91$ & 0.002 \\
\hline \multirow[t]{2}{*}{ PGR mRNA level } & 304 & 100 & 0.90 & $0.84-0.97$ & 0.003 & 0.91 & $0.85-0.99$ & 0.025 \\
\hline & & & & & & \multicolumn{3}{|c|}{ Addition to base model } \\
\hline $\begin{array}{l}\text { LAMP3 mRNA (as } \\
\text { categorized variable) }\end{array}$ & & & & & $<0.001$ & & & 0.032 \\
\hline Low & 102 & 34 & 1.00 & & & 1.00 & & \\
\hline Intermediate & 101 & 33 & 0.94 & $0.71-1.25$ & & 0.92 & $0.69-1.23$ & \\
\hline High & 101 & 33 & 1.57 & $1.18-2.09$ & & 1.37 & $1.01-1.86$ & \\
\hline
\end{tabular}

The expression levels of $\angle A M P 3$ were evaluated as categorized variables. Factors were added separately to the base model in the multivariate analysis. ${ }^{a}$ The multivariate analysis is stratified for menopausal status. ER and PGR levels were analyzed as log-transformed continuous variables.

study, these results indicate the UPR appears to play a significant role in resistance to anti-estrogen therapy.

The process that the UPR can induce to overcome stressful conditions is autophagy. Recently, autophagy has also been implicated in tamoxifen resistance. Overexpression of $B E C N 1$, a factor involved in the nucleation step of the autophagic cascade, rendered MCF7 cells more resistant to treatment with 4-hydroxytamoxifen (John et al. 2008). In addition, BECN1 was found to downregulate estrogenic signaling and growth response. Others studies have found that inhibition of autophagy, by siRNAs or chemicals, could sensitize breast cancer cells to tamoxifen (Samaddar et al. 2008, Qadir et al. 2008, Namgoong et al. 2010). Breast cancer cells that were cultured to tamoxifen resistance could be resensitized by autophagy inhibition (Samaddar et al. 2008), similar to the effects of LAMP3 knockdown. Whether the process of autophagy is a prosurvival or prodeath pathway has been controversial for some time (Hippert et al. 2006, Mazure \& Pouyssegur 2010, Mathew \& White 2011). Initially, autophagy is aimed at recycling energy in order to survive. However, when conditions become too harsh, even autophagy is not able to save cells and eventually death will occur. In tamoxifen treatment, it appears that autophagy is aimed at cell survival, as its inhibition via knockdown of autophagy-related genes as well as LAMP3 can sensitize cells to tamoxifen-induced death.

In this study, autophagy in LAMP3 knockdown cells was found to be compromised. Compared with negative control cells, LAMP3 knockdown cells had increased levels of both LC3B and p62. Also, immunocytochemical staining revealed that $L A M P 3$ knockdown cells had little colocalization of autophagosomes with lysosomes. LAMP3 is localized in the lysosomal membrane. The cytoplasmic tail of LAMP3 appears to be involved in the fusion of the autophagosome with the lysosome. Knockdown of LAMP3 leads to an inhibition of autophagic flux and therefore to an accumulation of LC3B and p62, leaving the induction of autophagy unaffected. These data are corroborated by its homologs LAMP1 and LAMP2, which are also involved in the lysosomal degradation pathway (Eskelinen et al. 2003). LAMP2-deficient cells are autophagy-inhibited as autophagic vacuoles accumulate (Tanaka et al. 2000). This accumulation causes the lysosomal glycogen

Published by Bioscientifica Ltd 
storage disorder Danon's disease. On the other hand, LAMP1-deficiency in knockout-mice had a relatively mild phenotype, possibly due to the compensation of LAMP1deficiency by increased levels of LAMP2 (Andrejewski et al. 1999). LAMPs are important in the response to cancer therapy. Knockdown of LAMP1 or LAMP2 was found to be sufficient to sensitize cells to anticancer drugs (Fehrenbacher et al. 2008) and knockdown of LAMP3 could significantly sensitize breast cancer cells to radiotherapy (Nagelkerke et al. 2013b).

In conclusion, LAMP3 is an important mediator of resistance to tamoxifen in breast cancer. Pharmacological inhibition of autophagy and the UPR, perhaps via LAMP3, may represent an attractive opportunity to increase the efficacy of tamoxifen in both tamoxifen-sensitive and -resistant ER-positive tumors.

\section{Declaration of interest}

The authors declare that there is no conflict of interest that could be perceived as prejudicing the impartiality of the research reported.

\section{Funding}

A M Sieuwerts, J A Foekens, and J W M Martens received financial support from Cancer Genomics Netherlands.

\section{Acknowledgements}

The authors thank Anne van Galen and Vanja de Weerd for helping with the RT-qPCR analysis. They especially thank Marion E Meijer-van Gelder and the surgeons, pathologists, and interns of the St Clara Hospital, Ikazia Hospital, St Fransiscus Gasthuis, Erasmus MC at Rotterdam, and Ruwaard van Putten Hospital at Spijkenisse for their assistance in collecting the tumor tissues and patient's clinical follow-up data. This study was conducted as a collaboration within the PathoBiology Group of the European Organisation for Cancer Research and Treatment.

\section{References}

van Agthoven T, Sieuwerts AM, Meijer-van Gelder ME, Look MP, Smid M, Veldscholte J, Sleijfer S, Foekens JA \& Dorssers LC 2009 Relevance of breast cancer antiestrogen resistance genes in human breast cancer progression and tamoxifen resistance. Journal of Clinical Oncology 27 542-549. (doi:10.1200/JCO.2008.17.1462)

van Agthoven T, Sieuwerts AM, Meijer D, Meijer-van Gelder ME, van Agthoven TL, Sarwari R, Sleijfer S, Foekens JA \& Dorssers LC 2010 Selective recruitment of breast cancer anti-estrogen resistance genes and relevance for breast cancer progression and tamoxifen therapy response. Endocrine-Related Cancer 17 215-230. (doi:10.1677/ ERC-09-0062)

Al-Rawashdeh FY, Scriven P, Cameron IC, Vergani PV \& Wyld L 2010 Unfolded protein response activation contributes to chemoresistance in hepatocellular carcinoma. European Journal of Gastroenterology \& Hepatology 22 1099-1105. (doi:10.1097/MEG.0b013e3283378405)

Altman DG, McShane LM, Sauerbrei W \& Taube SE 2012 Reporting Recommendations for Tumor Marker Prognostic Studies (REMARK):

http://erc.endocrinology-journals.org DOI: $10.1530 /$ ERC-13-0183
(C) 2014 Society for Endocrinology Printed in Great Britain explanation and elaboration. PLoS Medicine 9 e1001216. (doi:10.1371/ journal.pmed.1001216)

Andrejewski N, Punnonen EL, Guhde G, Tanaka Y, Lullmann-Rauch R, Hartmann D, von Figura K \& Saftig P 1999 Normal lysosomal morphology and function in LAMP-1-deficient mice. Journal of Biological Chemistry 274 12692-12701. (doi:10.1074/jbc.274.18.12692)

Bursch W, Ellinger A, Kienzl H, Torok L, Pandey S, Sikorska M, Walker R \& Hermann RS 1996 Active cell death induced by the anti-estrogens tamoxifen and ICI 164384 in human mammary carcinoma cells (MCF-7) in culture: the role of autophagy. Carcinogenesis 17 1595-1607. (doi:10.1093/carcin/17.8.1595)

Chen R, Dai RY, Duan CY, Liu YP, Chen SK, Yan DM, Chen CN, Wei M \& Li H 2011 Unfolded protein response suppresses cisplatin-induced apoptosis via autophagy regulation in human hepatocellular carcinoma cells. Folia Biologica 57 87-95.

Cole MP, Jones CT \& Todd ID 1971 A new anti-oestrogenic agent in late breast cancer. An early clinical appraisal of ICI46474. British Journal of Cancer 25 270-275. (doi:10.1038/bjc.1971.33)

Cook KL, Shajahan AN, Warri A, Jin L, Hilakivi-Clarke LA \& Clarke R 2012 Glucose-regulated protein 78 controls cross-talk between apoptosis and autophagy to determine antiestrogen responsiveness. Cancer Research 72 3337-3349. (doi:10.1158/0008-5472.CAN-12-0269)

Duan L, Motchoulski N, Danzer B, Davidovich I, Shariat-Madar Z \& Levenson VV 2011 Prolylcarboxypeptidase regulates proliferation, autophagy, and resistance to 4-hydroxytamoxifen-induced cytotoxicity in estrogen receptor-positive breast cancer cells. Journal of Biological Chemistry 286 2864-2876. (doi:10.1074/jbc.M110.143271)

Eskelinen EL, Illert AL, Tanaka Y, Schwarzmann G, Blanz J, Von Figura K \& Saftig P 2002 Role of LAMP-2 in lysosome biogenesis and autophagy. Molecular Biology of the Cell 13 3355-3368. (doi:10.1091/ mbc.E02-02-0114)

Eskelinen EL, Tanaka Y \& Saftig P 2003 At the acidic edge: emerging functions for lysosomal membrane proteins. Trends in Cell Biology 13 137-145. (doi:10.1016/S0962-8924(03)00005-9)

Fehrenbacher N, Bastholm L, Kirkegaard-Sorensen T, Rafn B, Bottzauw T, Nielsen C, Weber E, Shirasawa S, Kallunki T \& Jaattela M 2008 Sensitization to the lysosomal cell death pathway by oncogene-induced down-regulation of lysosome-associated membrane proteins 1 and 2 . Cancer Research 68 6623-6633. (doi:10.1158/0008-5472.CAN-08-0463)

Feldman DE, Chauhan V \& Koong AC 2005 The unfolded protein response: a novel component of the hypoxic stress response in tumors. Molecular Cancer Research 3 597-605. (doi:10.1158/1541-7786.MCR-05-0221)

Foekens JA, Portengen H, van Putten WL, Peters HA, Krijnen HL, Alexieva-Figusch J \& Klijn JG 1989 Prognostic value of estrogen and progesterone receptors measured by enzyme immunoassays in human breast tumor cytosols. Cancer Research 49 5823-5828.

Giuliano M, Schifp R, Osborne CK \& Trivedi MV 2011 Biological mechanisms and clinical implications of endocrine resistance in breast cancer. Breast 20 (Suppl 3) S42-S49. (doi:10.1016/ S0960-9776(11)70293-4)

Gomez BP, Riggins RB, Shajahan AN, Klimach U, Wang A, Crawford AC Zhu Y, Zwart A, Wang M \& Clarke R 2007 Human X-box binding protein-1 confers both estrogen independence and antiestrogen resistance in breast cancer cell lines. FASEB Journal 21 4013-4027. (doi:10.1096/fj.06-7990com)

Hayward JL, Carbone PP, Heuson JC, Kumaoka S, Segaloff A \& Rubens RD 1977 Assessment of response to therapy in advanced breast cancer: a project of the Programme on Clinical Oncology of the International Union Against Cancer, Geneva, Switzerland. Cancer 39 1289-1294. (doi:10.1002/1097-0142(197703)39:3 < 1289::AID-CNCR2820390340 $>3.0 . \mathrm{CO} ; 2-\mathrm{F})$

Hippert MM, O'Toole PS \& Thorburn A 2006 Autophagy in cancer: good, bad, or both? Cancer Research 66 9349-9351. (doi:10.1158/0008-5472. CAN-06-1597)

Igarashi T, Izumi H, Uchiumi T, Nishio K, Arao T, Tanabe M, Uramoto $\mathrm{H}$, Sugio K, Yasumoto K, Sasaguri Y et al. 2007 Clock and ATF4 
transcription system regulates drug resistance in human cancer cell lines. Oncogene 26 4749-4760. (doi:10.1038/sj.onc.1210289)

John S, Nayvelt I, Hsu HC, Yang P, Liu W, Das GM, Thomas T \& Thomas TJ 2008 Regulation of estrogenic effects by beclin 1 in breast cancer cells. Cancer Research 68 7855-7863. (doi:10.1158/0008-5472.CAN-07-5875)

Klionsky DJ \& Emr SD 2000 Autophagy as a regulated pathway of cellular degradation. Science 290 1717-1721. (doi:10.1126/science. 290.5497.1717)

Klionsky DJ, Abeliovich H, Agostinis P, Agrawal DK, Aliev G, Askew DS, Baba M, Baehrecke EH, Bahr BA, Ballabio A et al. 2008 Guidelines for the use and interpretation of assays for monitoring autophagy in higher eukaryotes. Autophagy 4 151-175.

Maass H, Jonat W, Stolzenbach G \& Trams G 1980 The problem of nonresponding estrogen receptor-positive patients with advanced breast cancer. Cancer 46 2835-2837. (doi:10.1002/1097. 0142(19801215)46:12+<2835::AID-CNCR2820461420 > 3.0.CO;2-M)

Mathew R \& White E 2011 Autophagy in tumorigenesis and energy metabolism: friend by day, foe by night. Current Opinion in Genetics \& Development 21 113-119. (doi:10.1016/j.gde.2010.12.008)

Mazure NM \& Pouyssegur J 2010 Hypoxia-induced autophagy: cell death or cell survival? Current Opinion in Cell Biology 22 177-180. (doi:10.1016/ j.ceb.2009.11.015)

Milani M, Rzymski T, Mellor HR, Pike L, Bottini A, Generali D \& Harris AL 2009 The role of ATF4 stabilization and autophagy in resistance of breast cancer cells treated with Bortezomib. Cancer Research 69 4415-4423. (doi:10.1158/0008-5472.CAN-08-2839)

Mizushima N, Yoshimori T \& Levine B 2010 Methods in mammalian autophagy research. Cell 140 313-326. (doi:10.1016/j.cell.2010.01.028)

Mujcic H, Rzymski T, Rouschop KM, Koritzinsky M, Milani M, Harris AL \& Wouters BG 2009 Hypoxic activation of the unfolded protein response (UPR) induces expression of the metastasis-associated gene LAMP3. Radiotherapy and Oncology 92 450-459. (doi:10.1016/j.radonc.2009.08.017)

Nagelkerke A, Mujcic H, Bussink J, Wouters BG, van Laarhoven HW, Sweep FC \& Span PN 2011 Hypoxic regulation and prognostic value of LAMP3 expression in breast cancer. Cancer 117 3670-3681. (doi:10.1002/cncr.25938)

Nagelkerke A, Bussink J, Mujcic H, Wouters BG, Lehmann S, Sweep FC \& Span PN 2013a Hypoxia stimulates migration of breast cancer cells via the PERK/ATF4/LAMP3-arm of the unfolded protein response. Breast Cancer Research 15 R2. (doi:10.1186/bcr3373)

Nagelkerke A, Bussink J, van der Kogel AJ, Sweep FC \& Span PN $2013 b$ The PERK/ATF4/LAMP3-arm of the unfolded protein response affects radioresistance by interfering with the DNA damage response. Radiotherapy and Oncology 108 415-421. (doi:10.1016/j.radonc.2013. 06.037)

Namgoong GM, Khanal P, Cho HG, Lim SC, Oh YK, Kang BS, Shim JH, Yoo JC \& Choi HS 2010 The prolyl isomerase Pin1 induces LC-3 expression and mediates tamoxifen resistance in breast cancer. Journal of Biological Chemistry 285 23829-23841. (doi:10.1074/jbc.M109.092874)

Osborne CK 1998 Tamoxifen in the treatment of breast cancer. New England Journal of Medicine 339 1609-1618. (doi:10.1056/ NEJM199811263392207)
Osborne CK, Yochmowitz MG, Knight WA III \& McGuire WL 1980 The value of estrogen and progesterone receptors in the treatment of breast cancer. Cancer 46 2884-2888. (doi:10.1002/1097. 0142(19801215)46:12+>2884::AID-CNCR2820461429>3.0.CO;2-U)

Pyrko P, Schonthal AH, Hofman FM, Chen TC \& Lee AS 2007 The unfolded

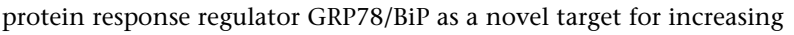
chemosensitivity in malignant gliomas. Cancer Research 67 9809-9816. (doi:10.1158/0008-5472.CAN-07-0625)

Qadir MA, Kwok B, Dragowska WH, To KH, Le D, Bally MB \& Gorski SM 2008 Macroautophagy inhibition sensitizes tamoxifen-resistant breast cancer cells and enhances mitochondrial depolarization. Breast Cancer Research and Treatment 112 389-403. (doi:10.1007/s10549-007-9873-4)

Riggs BL \& Hartmann LC 2003 Selective estrogen-receptor modulators mechanisms of action and application to clinical practice. New England Journal of Medicine 348 618-629. (doi:10.1056/NEJMra022219)

Rouschop KM, van den Beucken T, Dubois L, Niessen H, Bussink J, Savelkouls K, Keulers T, Mujcic H, Landuyt W, Voncken JW et al. 2010 The unfolded protein response protects human tumor cells during hypoxia through regulation of the autophagy genes MAP1LC3B and ATG5. Journal of Clinical Investigation 120 127-141. (doi:10.1172/ JCI40027)

Rzymski T, Milani M, Pike L, Buffa F, Mellor HR, Winchester L, Pires I, Hammond E, Ragoussis I \& Harris AL 2010 Regulation of autophagy by ATF4 in response to severe hypoxia. Oncogene 29 4424-4435. (doi:10.1038/onc.2010.191)

Samaddar JS, Gaddy VT, Duplantier J, Thandavan SP, Shah M, Smith MJ, Browning D, Rawson J, Smith SB, Barrett JT et al. 2008 A role for macroautophagy in protection against 4-hydroxytamoxifen-induced cell death and the development of antiestrogen resistance. Molecular Cancer Therapeutics 7 2977-2987. (doi:10.1158/1535-7163.MCT-080447)

Scriven P, Coulson S, Haines R, Balasubramanian S, Cross S \& Wyld L 2009 Activation and clinical significance of the unfolded protein response in breast cancer. British Journal of Cancer 101 1692-1698. (doi:10.1038/ sj.bjc.6605365)

Sieuwerts AM, Meijer-van Gelder ME, Timmermans M, Trapman AM, Garcia RR, Arnold M, Goedheer AJ, Portengen H, Klijn JG \& Foekens JA 2005 How ADAM-9 and ADAM-11 differentially from estrogen receptor predict response to tamoxifen treatment in patients with recurrent breast cancer: a retrospective study. Clinical Cancer Research $\mathbf{1 1}$ 7311-7321. (doi:10.1158/1078-0432.CCR-05-0560)

Tanabe M, Izumi H, Ise T, Higuchi S, Yamori T, Yasumoto K \& Kohno K 2003 Activating transcription factor 4 increases the cisplatin resistance of human cancer cell lines. Cancer Research 63 8592-8595.

Tanaka Y, Guhde G, Suter A, Eskelinen EL, Hartmann D, Lullmann-Rauch R, Janssen PM, Blanz J, von Figura K \& Saftig P 2000 Accumulation of autophagic vacuoles and cardiomyopathy in LAMP-2-deficient mice. Nature 406 902-906. (doi:10.1038/35022595)

Wouters BG \& Koritzinsky M 2008 Hypoxia signalling through mTOR and the unfolded protein response in cancer. Nature Reviews. Cancer $\mathbf{8}$ 851-864. (doi:10.1038/nrc2501)

Received in final form 4 November 2013

Accepted 12 November 2013 http://erc.endocrinology-journals.org DOI: 10.1530/ERC-13-0183
(C) 2014 Society for Endocrinology Printed in Great Britain
Published by Bioscientifica Ltd. 